\title{
Improving outcomes of percutaneous coronary interventions in patients with stable ischemic heart disease
}

\author{
Dhavalkumar B. Patel ${ }^{1}$, Rachit Shah ${ }^{1,2}$, Ion S. Jovin ${ }^{1}$ \\ ${ }^{1}$ Department of Medicine, McGuire Veterans' Affairs Medical Center and Virginia Commonwealth University, Richmond, VA, USA; ${ }^{2}$ Heart Health \\ Center and North Alabama Medical Center, Florence, AL, USA \\ Contributions: (I) Conception and design: All authors; (II) Administrative support: None; (III) Provision of study materials or patients: None; (IV) \\ Collection and assembly of data: None; (V) Data analysis and interpretation: None; (VI) Manuscript writing: All authors; (VII) Final approval of \\ manuscript: All authors. \\ Correspondence to: Ion S. Jovin, MD, FSCAI. Department of Medicine, Virginia Commonwealth University, McGuire VAMC, 1201 Broad Rock \\ Boulevard, Richmond, VA 23249, USA. Email: isjovin@yahoo.com.
}

\begin{abstract}
Percutaneous coronary intervention (PCI) is a common cardiac procedure and there have been significant advances in the technologies over past decades that have improved the safety of these procedures. Various clinical trials and meta-analyses have shown that PCIs are associated with improved outcomes, especially among patients with acute coronary syndromes. However, the clinical benefit of PCIs among patients with stable ischemic heart disease (SIHD) other than improvement in anginal symptoms is less well established. The patients who have a significant burden of ischemia may benefit the most from revascularization. The achievement of complete revascularization, appropriate technique for stent deployment and intracoronary imaging during these procedures also can have a significant impact on the clinical outcomes. Moreover, patients with coronary artery disease should be managed with appropriate medical therapy after the PCIs. The procedural and non-procedural factors should be taken into consideration in order to optimize outcomes for patients with SIHD being treated with PCIs.
\end{abstract}

Keywords: Stable ischemic heart disease (SIHD); percutaneous coronary intervention (PCI); clinical outcomes

Submitted Sep 30, 2019. Accepted for publication Nov 01, 2019.

doi: $10.21037 /$ jtd.2019.11.17

View this article at: http://dx.doi.org/10.21037/jtd.2019.11.17

Percutaneous coronary intervention (PCI) is one of the most common cardiac procedure performed for the treatment of stable ischemic heart disease (SIHD) and acute coronary syndromes. Prior to the first angioplasty performed by Gruentzig in 1977, coronary artery bypass grafting (CABG) was the only modality of coronary revascularization. Since the advent of coronary angioplasty, there has been considerable progress in the equipment, techniques, ancillary imaging, and periprocedural pharmacotherapy which has improved the safety of coronary interventions. Previous trials of comparing CABG and PCI for high risk, multivessel coronary artery disease showed superiority of CABG mainly by decreasing the need for target lesion revascularization (1-3). With the technological advancement and introduction of second-generation drug-eluting stents
(DES), outcomes of PCI continue to get closer to those of bypass surgery (4). However, in large-scale clinical trials, PCI has not shown to reduce myocardial infarction (MI) or mortality compared to medical therapy when it is performed for SIHD $(5,6)$. The main benefit of these procedures was the reduction in anginal symptoms and improvement in the quality of life, though, this has been contradicted by the Objective Randomised Blinded Investigation with Optimal Medical therapy of Angioplasty in Stable angina (ORBITA) trial (7). The medical community continues to explore ways to improve outcomes of PCI among patients with SIHD. Factors such as patient selection, technical aspects of the procedure and post procedure management may influence PCI outcomes. This paper reviews procedural and nonprocedural factors which can improve outcomes of PCI 
performed for SIHD patients.

\section{Patient selection based on ischemic burden}

PCI has proven to be effective and is associated with reduced cardiovascular mortality in high-risk clinical scenarios such as unstable angina or acute coronary syndromes $(8,9)$. However, the role of elective PCI among patients with stable coronary artery disease to reduce the risk of MI and mortality is unclear $(5,6)$. The Clinical Outcomes Utilizing Revascularization and Aggressive Drug Evaluation (COURAGE) trial failed to show a significant difference of MI and mortality among SIHD patients treated with PCI in association with optimal medical therapy (OMT) compared to OMT alone (5). The COURAGE trial was criticized due to its enrollment process leading to selection bias by exclusion of potentially high risk patients, and high crossover rates (10). However, these findings have led to a decrease in the number of revascularization procedures, and a 'medical therapy first' approach is recommended and preferred, particularly for the low risk patients (11). The nuclear substudy of the COURAGE trial showed that the addition of PCI to OMT results in a greater reduction in inducible ischemia along with freedom from angina (5) in higher risk patients. Moreover, $>5 \%$ reduction in ischemic burden and lower residual ischemia after revascularization or medical therapy predicted a reduced risk of MI and death; the benefit of therapy was greatest among patients with more severe ischemia at baseline. Although this small subgroup analysis did not show a significant reduction in clinical events with the addition of PCI to OMT regardless of the severity of baseline ischemia, these findings were hypothesis-generating. In the large observational study by Hachamovitch et al., involving 13,969 patients with a long-term follow up, early revascularization was associated with improved survival among patients with significant ischemia without myocardial scar while medical therapy was superior for patients with minimal ischemia (12). Although the practice guidelines recommend to consider the degree of myocardial ischemia quantified on noninvasive testing prior to considering cardiac catheterization (13), this recommended strategy has been underutilized (14). An analysis of 23,887 Medicare patients by Lin et al. showed that the majority of the patients with SIHD patients did not have documented ischemia by noninvasive testing prior to undergoing elective PCI (14). The International Study of Comparative Health Effectiveness with Medical and Invasive Approaches (ISCHEMIA) trial that was started in 2012 and included patients with moderate to severe ischemic burden at baseline will help to elucidate if PCI will improve clinical outcomes when guided by the burden of ischemia demonstrated by non-invasive testing (15).

\section{Invasive evaluation of ischemia}

Fractional flow reserve (FFR) measures the pressure gradient across a coronary artery stenosis to quantify the relative flow reserve at maximum myocardial hyperemia (16). An FFR ratio of less than $0.75-0.80$ reveals hemodynamically significant flow limiting stenosis and is associated with inducible myocardial ischemia (16). The Functional Flow Reserve versus Angiography for Multivessel Evaluation (FAME) trial showed that routine measurement of FFR to guide PCI significantly reduced the rate of death, MI and need for repeat revascularization procedures compared to patients who underwent PCI based on angiographic results (17). The composite outcome of death and MI was also reduced. Moreover, patients who underwent ischemia driven PCI had fewer stents, and decreased contrast use. In the FAME2 trial, which randomized patients with hemodynamically significant coronary stenosis based on abnormal FFR $(<0.80)$ to PCI versus OMT, recruitment was halted prematurely after there was significant reduction in the primary end point (death, MI, urgent revascularization) noted among patients who underwent PCI compared to medical therapy (18). The difference of outcomes was primarily driven by increased number of urgent revascularization procedures in the medical therapy group which was triggered by abnormal biomarkers and/or ECG changes. Moreover, among $25 \%$ of the patients in this trial who had abnormal FFR $<0.8$, there was no evidence of significant obstructive disease based on angiography (18). Thus, angiography alone, without using FFR, may underestimate clinically significant ischemic lesions, which, if left untreated, may lead to worse clinical outcomes. In a meta-analysis of 7 studies involving 49,517 patients, FFR guided PCI was associated with lower major adverse cardiovascular events (MACE), death, MI, and repeat revascularization compared to angiography guided PCI (19). Previous trials which enrolled patients primarily based on angiographic findings irrespective of the degree of ischemia on noninvasive testing, have failed to show a benefit of revascularization compared to medical therapy for the patient with stable coronary artery disease $(5,6)$. PCI for hemodynamically significant disease by FFR (when FFR of 0.80 or less) is superior compared to medical therapy, particularly mitigating the need for urgent 
revascularization $(18,19)$.

The instantaneous wave free ratio (iFR) is a recently developed physiological index which measures the resting pressure gradient across coronary stenosis during the portion of diastole during the period of low and stable microvascular resistance (20). Studies have shown that the iFR has similar diagnostic accuracy as FFR as an independent measure of ischemia without the need to administer adenosine leading to lower rates of adverse reactions and chest discomfort during the procedure (21). In summary, ischemia guided PCI using FFR and iFR may lead to superior outcomes and should be preferred over angiography guided PCI, especially in patients with borderline severe lesions.

\section{Complete revascularization improves outcomes}

The residual stress-inducible ischemia after revascularization or medical therapy is associated with an increased risk of adverse clinical events and the goal of revascularization is to minimize residual ischemia $(5,22)$. The benefit of complete revascularization was recognized in initial trials of patients undergoing CABG. The subgroup analysis of the Coronary Artery Surgery Study (CASS) registry showed that patients who had more than 3 grafts had better survival outcomes than patients who received 1 or 2 grafts (23). In a metaanalysis of 89,883 patients, complete revascularization was associated with lower mortality, MI and need for repeat revascularization procedures irrespective of revascularization strategy, and it was more frequently achieved with CABG than with PCI (24). The major randomized controlled trials involving patients with multivessel coronary artery disease showed that CABG was superior to PCI, mainly because of higher rates of repeat revascularization in the PCI group $(1,2)$. However, a pooled analysis of 3,212 patients, from the randomized comparison of CABG and Everolimus Eluting Stent Implantation in the Treatment of Patients with Multivessel Coronary Artery Disease (BEST) trial, the Synergy between Percutaneous Coronary Intervention with Taxus and Cardiac Surgery (SYNTAX) trial, and the Premier of Randomized Comparison of Bypass Surgery vs. Angioplasty Using Sirolimus-Eluting Stent in Patients with Left Main Coronary Artery Disease (PRECOMBAT) trial, showed that patients achieving complete revascularization after PCI had similar outcomes and long term survival rates compared to patients who underwent CABG and achieved complete revascularization. On other hand, patients with incomplete revascularization after PCI had lower survival rates (25). The practice guidelines recommend to consider the ability to achieve complete revascularization as one of the factor into decision making of revascularization strategy for patients with multivessel coronary artery disease (26). The SYNTAX score, which is the surrogate marker for disease complexity, is widely used in decision algorithms while considering revascularization options (27). In the SYNTAX trial, patients with the lowest SYNTAX score had similar rates of complete revascularization between PCI and CABG and no statistically significant difference in clinical events. However, patients who underwent PCI in the presence of higher SYNTAX score had higher rates of incomplete revascularization and major adverse cardiac and cerebrovascular events $(1,27)$. The patients with complex coronary disease such as chronic total occlusions (CTO), bifurcation or trifurcation lesions, heavy calcification, and diffuse disease had higher SYNTAX scores and were more likely to have incomplete revascularization with either revascularization strategies, but more so with PCI (27). The major factor for not achieving complete revascularization after PCI in the SYNTAX trial was the presence of CTO $(27,28)$. The techniques to recanalize CTOs have evolved significantly over the past 5-10 years and success rates have been reported to be as high as $80-90 \%$ by experienced operators (29). Although there is no large randomized controlled trial to show that CTO interventions improve outcomes, CTO interventions can be considered after considering risk and benefit ratio in patients with severe symptoms, high grade ischemia and viable myocardium $(13,22)$. Thus, the achievement of complete revascularization is an important factor that is associated with improvement in the long-term outcomes in patients undergoing percutaneous but also surgical revascularization. In patients with multivessel coronary artery disease who are not candidates for CABG, percutaneous interventions should aim at achieving minimal residual ischemia. PCI should be considered for all coronary stenoses in major coronary arteries contributing to high ischemic burden, and FFR may be useful in evaluating lesions that are functionally significant and merit interventions.

\section{Coronary stenting and intervention techniques}

The bare metal stents reduced the rates of balloon angioplasty related complications such as acute vessel closure from elastic recoil and dissections and improved clinical outcomes, but neointimal hyperplasia and subsequent restenosis was the major limitation (30). DES were developed to overcome this limitation by inhibiting 
neointimal proliferation and it was associated with reduced rate of restenosis, but an increased risk of late stent thrombosis (31). The peri-strut inflammation and impaired endothelialization after DES implantation was associated with delayed stent strut coverage and an increased risk of stent thrombosis (32). Newer, second generation DES which have thinner struts and an optimized release of antiproliferative drugs leading to rapid endothelialization (33) are associated with decreased late stent thrombosis along with a reduction in restenosis rates (33).

The development of newer generation stent technology has resulted in improved outcomes, however, there remains considerable variation in the balloon inflation techniques for stent deployment including balloon compliance, inflation pressures and length of inflation that may impact short and long-term outcomes (4). Less than optimal techniques for stent deployment may lead to suboptimal stent expansion which is associated with an increased rate of stent thrombosis and restenosis (34). A common practice is predilation for stent delivery, then rapid inflation and deflation of stent balloon usually for 30 seconds or less with the subsequent use of a non-compliant balloon for post dilatation being performed routinely or in some cases only if angiography shows suboptimal stent expansion. Although post-dilatation may theoretically optimize stent expansion and decrease malapposition, it has never been proven to be effective in a large scale clinical study. In fact, an analysis of the Swedish Coronary Angiography and Angioplasty Registry data raised concern regarding increased restenosis rate with post dilatation (35). Moreover, the availability of low-profile stent delivery systems leads to the possibility of direct stenting without predilation of the lesion. In a randomized controlled trial direct stenting was safe, successful and had similar outcomes, though $6-15$ percent of patients in the direct stenting group required predilation due to inability to cross the lesion directly with the stent. In a meta-analysis involving 10,900 patients, direct stenting was associated with lower rates of MI and target lesion revascularization (36). The optimal stent expansion can be achieved with prolonged high pressure balloon inflation during stent deployment. Stents are typically deployed with high pressure inflation at around 12-16 atm and lower pressure is used in the presence of significant vessel tapering, or when there is a concern for proximal or distal edge injury. Data from the Swedish registry showed a stepwise reduction in restenosis and stent thrombosis rates when inflation pressure increased up to 20-21 atm but at higher inflation pressure greater than $21 \mathrm{~atm}$ there was an increase in clinical events (35). Although the optimal duration of balloon inflation depends on the length of the lesion as well as plaque composition, in general, studies showed that a longer duration of balloon inflation was beneficial as it can overcome resistance of fibrocalcific plaque (35). In the study by Cook et al., the stent balloon was inflated until pressure was stabilized and it was termed as pressure optimization protocol. The average inflation duration in this study for the patient who had stent deployment based on pressure optimization protocol was 104 seconds, and it showed reduced target vessel revascularization rates compared to patients who underwent rapid inflation and deflation (37). A meta-analysis of seven studies involving 341 patients showed that prolonged balloon inflation was associated with improved stent expansion with increased minimal stent diameter and area compared to shorter inflation (38). In spite of the current evidence showing benefit of prolonged inflation, there seems to be some reluctance among physicians to perform prolonged inflation, due to increased time of procedure and the potential for hemodynamic compromise due to ischemia during balloon inflation. However, the above-mentioned study showed that in most conditions prolonged inflation is safe and provides clinical benefit.

\section{Imaging guidance for stent implantation}

Even though angiography visualizes only coronary lumen and has several limitations, it is the most widely technique used to assess lesion characteristics and severity, and to guide coronary interventions. Two catheter-based imaging techniques, intravascular ultrasound (IVUS) and optical coherence tomography (OCT), with an ability to visualize lumen and vessel wall and to characterize lesion morphology, have been used to assist coronary interventions. Anatomical assessment of coronary lesions with these imaging techniques prior to intervention may provide valuable information to guide appropriate PCI strategies, and stent sizing. It also helps to optimize stent deployment by evaluating stent expansion, malaposition of stent struts, geographic miss and identifying immediate post PCI complications such as edge dissection, hematoma, and thrombus $(39,40)$.

The CRUISE (Can Routine Ultrasound Influence Stent Expansion) study showed greater minimal lumen diameter and minimal stent area among patients who underwent 
IVUS guided PCI (41). This resulted into lower rates of clinically driven target vessel revascularization (41). The ADAPT-DES (The Assessment of Dual Antiplatelet Therapy with Drug-Eluting Stents) study showed in a propensity-adjusted analysis that patients who underwent peri-procedure IVUS assessment had lower rates of stent thrombosis, MI and target vessel revascularization (42). In this study, longer stents, larger size balloons/stents, and higher inflation pressures were used in IVUS guided PCI group without increasing risk of peri-procedure MI. The study also showed that the greatest absolute benefit of using IVUS was noted in patients with acute coronary syndromes and with complex coronary anatomy (42). The HORIZONS-AMI IVUS sub study showed that early stent thrombosis after primary PCI for ST elevation MI was associated with small residual luminal area, under expansion, thrombus protrusion, and edge dissection (43). IVUS may help to identify these complications and leads to additional post-procedure interventions to remediate them. The meta-analysis of the seven randomized trials (3,192 patients) of IVUS guided versus angiography guided DES placement showed that the use of IVUS was associated with a lower rate of MI, stent thrombosis and ischemia driven target lesion revascularization (44). The meta-analysis also showed that more patients in the IVUS guided PCI group had post dilatation which lead to significantly larger post procedure minimal lumen diameter and greater reduction in the diameter stenosis. In a randomized controlled trial, Kim et al. showed that IVUS guided CTO interventions were associated with a lower rate of MACE along with a reduced composite endpoint of cardiac death and MI (45). In this trial, although target vessel revascularization was lower in the IVUS guided intervention group, it was statistically not significant. The Minimizing Contrast Utilization with IVUS Guidance in Coronary Angioplasty (MOZART) trial showed that IVUS guidance can minimize the need for contrast use and reduce the risk of post PCI contrast induced renal insufficiency (46). For patients at significantly higher risk of progression of renal insufficiency, PCI can be safely performed without contrast agent using IVUS guidance pre and post stent deployment (47).

OCT has superior resolution compared to IVUS at the expense of limited depth of penetration and may be unable to resolve the external elastic membrane accurately. The fast pullback acquisition and fully automated volumetric lumen segmentation with angiography co-registration makes the OCT very precise for stent length estimation (40). Initial studies showed that IVUS guidance was associated with a larger minimal stent area, likely because IVUS tends to overestimate lumen area. A subsequent randomized controlled trial (ILUMIEN III) showed that OCT guided PCI using the external elastic lamina as a reference segment was feasible and resulted in a minimal stent area similar to that of IVUS guided PCI group (48). The Optical Frequency Domain Imaging Versus IVUS in percutaneous coronary intervention (OPINION) trial which randomized 817 patients to OCT guided and IVUS guided PCI showed no difference in clinical endpoints, and OCT was noninferior to IVUS (49). In retrospective studies, OCT guided PCI was associated with improved procedural outcomes, inhospital MACE and also long term survival compared to angiography guided PCI (50).

In the Observational Study of Optical Coherence Tomography in Patients Undergoing Fractional Flow Reserve and Percutaneous Coronary Intervention(ILUMIEN I) study, patients who underwent pre-PCI OCT, the procedure was altered in $55 \%$ of patients by selecting different stent lengths (51). Also after achieving clinically satisfactory stent implantation using angiographic guidance, post PCI OCT showed malapposition (14.5\%), under-expansion $(7.6 \%)$, edge dissection $(1.7 \%)$, thrombus and tissue protrusion (1\%) which lead to post PCI optimization in $25 \%$ of patients with post dilatation or additional stent deployment. Similarly, the Does Optical Coherence Tomography Optimize Results of Stenting (DOCTORS) trial showed in patients who presented with non ST segment elevated MI, that OCT use led the operator to select a post-procedure optimization strategy in $50 \%$ of patients compared to $22 \%$ in the angiographyguided PCI group, leading to more post dilatation, lower residual stenosis and higher post procedure FFR (52). The study showed that OCT-guided procedures were associated with a higher volume of contrast use as this imaging technique requires injection of contrast during pullback (52).

\section{Post PCI management}

The patients with obstructive coronary artery disease after PCI will need to be followed on regular basis for optimization of medical therapy and risk factors, and should be encouraged to adopt lifestyle modifications such as smoking cessation, regular exercise, and weight reduction (53). These measures have a significant role in preventing future cardiovascular as well as cerebrovascular events and improving quality of life $(13,22,53)$. Dual antiplatelet 


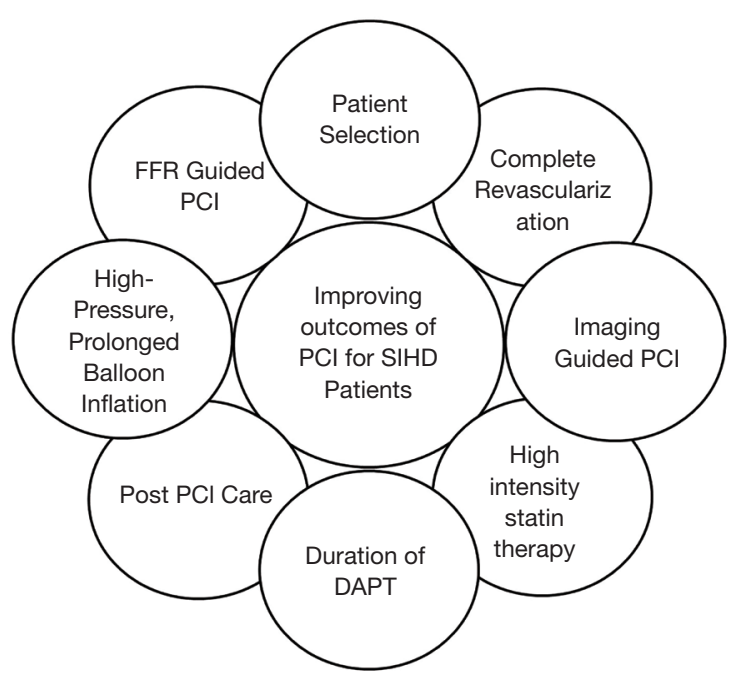

Figure 1 Factors that can lead to optimized outcomes in patient undergoing PCI. FFR, fractional flow reserve; PCI, percutaneous coronary intervention; SIHD, stable ischemic heart disease; DAPT, dual antiplatelet therapy.

therapy with aspirin and P2Y12 inhibitor is required after PCI with stent implantations to prevent stent thrombosis. However, the optimal duration of dual antiplatelet therapy (DAPT) for patients undergoing PCI with DES for SIHD is uncertain (53). Newer generation DES promote vascular healing and the thin struts allow a rapid endothelialization and thus, shorter courses of DAPT therapy may be reasonable, particularly for patients at higher risk of bleeding $(54,55)$. Randomized controlled trials showed similar rates of stent thrombosis in patients who received shorter courses ( 3 to 6 months) of DAPT compared to standard 12 months of DAPT $(54,55)$. The ACC/AHA guideline updates in 2016 recommended 6 months of DAPT therapy (class I recommendations) after DES and with consideration for extended duration of DAPT for selected patients (class IIb recommendations) (53). The benefit of extended duration of DAPT for up to 30 months was first demonstrated in the Dual Antiplatelet Therapy (DAPT) Study (56). In this trial, additional 18 months of DAPT therapy after PCI with DES significantly reduced the risk of stent thrombosis and MI at the expense of increased risk of bleeding (56). The allcause mortality was higher with the use of DAPT for up to 30 months. The DAPT score can predict the risk of ischemic events after PCI and can help identify patients who will have greater benefit for continuation of DAPT beyond 12 months (57). This score has been validated by many registries and patients with a DAPT score of 2 or greater are noted to have a favorable risk/benefit ratio for the use of prolonged DAPT (57). Thus, the decision to continue DAPT after PCI beyond 6 months should be individualized for each patient taking into consideration the risk of ischemic events and bleeding. For patients on oral anticoagulation therapy, the addition of DAPT can cause 2to 3 -fold increased risk of bleeding complications (58). The WOEST trial showed that among the patients taking oral anticoagulation, the use of clopidogrel without aspirin was associated with a lower risk of bleeding and similar rates of stent thrombosis (56). Another randomized controlled trial showed similar rates of ischemic events and bleeding with the reduced duration of triple therapy (aspirin, clopidogrel, and anticoagulation) to 6 weeks versus 6 months of triple therapy (59). The practice guideline recommended that the duration of triple therapy should be as short as possible and only dual therapy with oral anticoagulation and P2Y12 inhibitor should be used for patients at higher risk of bleeding.

Statin therapy, apart from reducing cholesterol levels, has pleiotropic effects such as reduced vascular inflammation, improved endothelial function and reduced atherosclerotic plaque progression (60). Statins have been extensively studied and have been shown to be associated with favorable long-term outcomes among patients with established coronary artery disease (61). Incomplete endothelialization following DES implantation is associated with an increased risk of stent thrombosis (32). In a porcine model, the pretreatment with atorvastatin has been shown to facilitate vascular healing by reducing inflammation improving neointimal proliferation and endothelialization after sirolimus eluting stent implantation (62). The randomized OCT study showed that patients treated with high dose statin had a lower percentage of uncovered stent struts (63). Compared to low intensity statin, high intensity statin after PCI may reduce rates of restenosis, stent thrombosis, and improves cardiovascular outcomes (64-66).

In summary (Figure 1), patients with moderate to high burden of ischemia by non-invasive testing may benefit from revascularization and these patients should undergo cardiac catheterization to evaluate the coronary anatomy. The hemodynamically significant coronary stenoses in the major epicardial arteries leading to a large area of ischemic myocardium should be targets for intervention. FFR and iFR are still unsurpassed when compared to noninvasive techniques to diagnose ischemia causing coronary stenosis, 
and remain the gold standard to predict clinical benefit of intervention. FFR guided PCI is superior to angiography guided PCI. The high pressure, prolonged stent balloon inflation for stent deployment results in better stent expansion and apposition of stent struts that is associated with improved outcomes. Imaging guided PCI using IVUS or OCT optimizes stent apposition and expansion and it is associated with greater minimal stent area and lower residual stenosis. Though intravascular imaging may increase fluoroscopy time and length of procedure, it is safe, feasible and associated with lower rates of mortality, MI and target lesion revascularization in some but not all studies. The complex and high-risk coronary lesions may benefit the most from pre- and post-intervention imaging assessment. Optimization of medical therapy for coronary artery disease is essential. The trade-off between the risk of ischemic events and bleeding should be considered in determining duration of DAPT and the use of triple therapy should be used only in selected patients for the shortest possible duration. The high intensity statin therapy facilitates vascular healing after DES implantation and reduces the risk of cardiovascular events.

\section{Acknowledgments}

Funding: None.

\section{Footnote}

Provenance and Peer Review: This article was commissioned by the Guest Editor (Ion S. Jovin) for the series "Interventional Cardiology" published in Fournal of Thoracic Disease. The article was sent for external peer review organized by the Guest Editor and the editorial office.

Conflicts of Interest: All authors have completed the ICMJE uniform disclosure form (available at http://dx.doi. org/10.21037/jtd.2019.11.17). The series "Interventional Cardiology" was commissioned by the editorial office without any funding or sponsorship. ISJ served as the unpaid Guest Editor of the series. The other authors have no other conflicts of interest to declare.

Ethical Statement: The authors are accountable for all aspects of the work in ensuring that questions related to the accuracy or integrity of any part of the work are appropriately investigated and resolved.
Open Access Statement: This is an Open Access article distributed in accordance with the Creative Commons Attribution-NonCommercial-NoDerivs 4.0 International License (CC BY-NC-ND 4.0), which permits the noncommercial replication and distribution of the article with the strict proviso that no changes or edits are made and the original work is properly cited (including links to both the formal publication through the relevant DOI and the license). See: https://creativecommons.org/licenses/by-nc-nd/4.0/.

\section{References}

1. Serruys PW, Morice MC, Kappetein AP, et al. Percutaneous coronary intervention versus coronary-artery bypass grafting for severe coronary artery disease. $\mathrm{N}$ Engl J Med 2009;360:961-72.

2. Park SJ, Ahn JM, Kim YH, et al. Trial of everolimuseluting stents or bypass surgery for coronary disease. $\mathrm{N}$ Engl J Med 2015;372:1204-12.

3. Kapur A, Hall RJ, Malik IS, et al. Randomized comparison of percutaneous coronary intervention with coronary artery bypass grafting in diabetic patients. 1-year results of the CARDia (Coronary Artery Revascularization in Diabetes) trial. J Am Coll Cardiol 2010;55:432-40.

4. Jovin IS, Vetrovec GW. Stent "Hygiene". Catheter Cardiovasc Interv 2018;92:881-2.

5. Shaw LJ, Berman DS, Maron DJ, et al. Optimal medical therapy with or without percutaneous coronary intervention to reduce ischemic burden: results from the Clinical Outcomes Utilizing Revascularization and Aggressive Drug Evaluation (COURAGE) trial nuclear substudy. Circulation 2008;117:1283-91.

6. BARI 2D Study Group, Frye RL, August P, et al. A randomized trial of therapies for type 2 diabetes and coronary artery disease. N Engl J Med 2009;360:2503-15.

7. Al-Lamee R, Thompson D, Dehbi HM, et al. Percutaneous coronary intervention in stable angina (ORBITA): a double-blind, randomised controlled trial. Lancet 2018;391:31-40.

8. Keeley EC, Boura JA, Grines CL, et al. Primary angioplasty versus intravenous thrombolytic therapy for acute myocardial infarction: a quantitative review of 23 randomised trials. Lancet 2003;361:13-20.

9. Mehta SR, Cannon CP, Fox KA, et al. Routine vs selective invasive strategies in patients with acute coronary syndromes: a collaborative meta-analysis of randomized trials. JAMA 2005;293:2908-17. 
10. Kereiakes DJ, Teirstein PS, Sarembock IJ. The truth and consequences of the COURAGE trial. J Am Coll Cardiol 2007;50:1598-603.

11. Ahmed B, Dauerman HL, Piper WD, et al. Recent changes in practice of elective percutaneous coronary intervention for stable angina. Circ Cardiovasc Qual Outcomes 2011;4:300-5.

12. Hachamovitch R, Rozanski A, Shaw LJ, et al. Impact of ischaemia and scar on the therapeutic benefit derived from myocardial revascularization vs. medical therapy among patients undergoing stress-rest myocardial perfusion scintigraphy. Eur Heart J 2011;32:1012-24.

13. Patel MR, Calhoon JH, Dehmer GJ, et al. ACC/ AATS/AHA/ASE/ASNC/SCAI/SCCT/STS 2017 appropriate use criteria for coronary revascularization in patients with stable ischemic heart disease: a report of the American College of Cardiology Appropriate Use Criteria Task Force, American Association for Thoracic Surgery, American Heart Association, American Society of Echocardiography, American Society of Nuclear Cardiology, Society for Cardiovascular Angiography and Interventions, Society of Cardiovascular Computed Tomography, and Society of Thoracic Surgeons. J Am Coll Cardiol 2017;69:2212-41.

14. Lin GA, Dudley RA, Lucas FL, et al. Frequency of stress testing to document ischemia prior to elective percutaneous coronary intervention. JAMA 2008;300:1765-73.

15. Hochman JS, Reynolds HR, Bangalore S, et al. Baseline Characteristics and Risk Profiles of Participants in the ISCHEMIA Randomized Clinical Trial. JAMA Cardiol 2019;4:273-86.

16. Pijls NH, Van Gelder B, Van der Voort P, et al. Fractional flow reserve. A useful index to evaluate the influence of anvepicardial coronary stenosis on myocardial blood flow. Circulation 1995;92:3183-93.

17. Tonino PA, De Bruyne B, Pijls NH, et al. Fractional flow reserve versus angiography for guiding percutaneous coronary intervention. N Engl J Med 2009;360:213-24.

18. De Bruyne B, Pijls NH, Kalesan B, et al. Fractional flow reserve-guided PCI versus medical therapy in stable coronary disease. N Engl J Med 2012;367:991-1001.

19. Zhang D, Lv S, Song X, et al. Fractional flow reserve versus angiography for guiding percutaneous coronary intervention: a meta-analysis. Heart 2015;101:455-62.

20. Sen S, Escaned J, Malik IS, et al. Development and validation of a new adenosine-independent index of stenosis severity from coronary wave-intensity analysis: results of the ADVISE (ADenosine Vasodilator
Independent Stenosis Evaluation) study. J Am Coll Cardiol 2012;59:1392-402.

21. Götberg M, Christiansen EH, Gudmundsdottir IJ et al. Instantaneous Wave-free Ratio versus Fractional Flow Reserve to Guide PCI. N Engl J Med 2017;376:1813-23.

22. Windecker S, Kolh P, Alfonso F, et al. 2014 ESC/EACTS Guidelines on myocardial revascularization: The Task Force on Myocardial Revascularization of the European Society of Cardiology (ESC) and the European Association for Cardio-Thoracic Surgery (EACTS)Developed with the special contribution of the European Association of Percutaneous Cardiovascular Interventions (EAPCI). Eur Heart J 2014;35:2541-619.

23. Bell MR, Gersh BJ, Schaff HV, et al. Effect of completeness of revascularization on long-term outcome of patients with three-vessel disease undergoing coronary artery bypass surgery. A report from the Coronary Artery Surgery Study (CASS) Registry. Circulation 1992;86:446-57.

24. Garcia S, Sandoval Y, Roukoz H, et al. Outcomes after complete versus incomplete revascularization of patients with multivessel coronary artery disease: a meta-analysis of 89,883 patients enrolled in randomized clinical trials and observational studies. J Am Coll Cardiol 2013;62:1421-31.

25. Ahn JM, Park DW, Lee CW, et al. Comparison of Stenting Versus Bypass Surgery According to the Completeness of Revascularization in Severe Coronary Artery Disease: PatientLevel Pooled Analysis of the SYNTAX, PRECOMBAT, and BEST Trials. JACC Cardiovasc Interv 2017;10:1415-24.

26. Fihn SD, Gardin JM, Abrams J, et al. 2012 ACCF/AHA/ ACP/AATS/PCNA/SCAI/STS guideline for the diagnosis and management of patients with stable ischemic heart disease: executive summary: a report of the American College of Cardiology Foundation/American Heart Association task force on practice guidelines, and the American College of Physicians, American Association for Thoracic Surgery, Preventive Cardiovascular Nurses Association, Society for Cardiovascular Angiography and Interventions, and Society of Thoracic Surgeons. Circulation 2012;126:3097-137.

27. Head SJ, Mack MJ, Holmes DR Jr, et al. Incidence, predictors and outcomes of incomplete revascularization after percutaneous coronary intervention and coronary artery bypass grafting: a subgroup analysis of 3-year SYNTAX data. Eur J Cardiothorac Surg 2012;41:535-41.

28. Farooq V, Serruys PW, Garcia-Garcia HM, et al. The negative impact of incomplete angiographic revascularization on clinical outcomes and its association with total occlusions: the SYNTAX (Synergy Between 
Percutaneous Coronary Intervention with Taxus and Cardiac Surgery) trial. J Am Coll Cardiol 2013;61:282-94.

29. Sapontis J, Salisbury AC, Yeh RW, et al. Early Procedural and Health Status Outcomes After Chronic Total Occlusion Angioplasty: A Report From the OPEN-CTO Registry (Outcomes, Patient Health Status, and Efficiency in Chronic Total Occlusion Hybrid Procedures). JACC Cardiovasc Interv 2017;10:1523-34.

30. Fischman DL, Leon MB, Baim DS, et al. A randomized comparison of coronary-stent placement and balloon angioplasty in the treatment of coronary artery disease. Stent Restenosis Study Investigators. N Engl J Med 1994;331:496-501.

31. Lagerqvist B, James SK, Stenestrand U, et al. Long-term outcomes with drug-eluting stents versus bare-metal stents in Sweden. N Engl J Med 2007;356:1009-19.

32. Finn AV, Nakazawa G, Joner $M$, et al. Vascular responses to drug eluting stents: importance of delayed healing. Arterioscler Thromb Vasc Biol 2007;27:1500-10.

33. Tada T, Byrne RA, Simunovic I, et al. Risk of stent thrombosis among bare-metal stents, first-generation drug-eluting stents, and second-generation drug-eluting stents: results from a registry of 18,334 patients. JACC Cardiovasc Interv 2013;6:1267-74.

34. Fujii K, Carlier SG, Mintz GS, et al. Stent underexpansion and residual reference segment stenosis are related to stent thrombosis after sirolimus-eluting stent implantation: an intravascular ultrasound study. J Am Coll Cardiol 2005;45:995-8.

35. Fröbert O, Sarno G, James SK, et al. Effect of stent inflation pressure and post-dilatation on the outcome of coronary artery intervention. A report of more than 90,000 stent implantations. PLoS One 2013;8:e56348.

36. Magalhaes MA, Minha S, Lhermusier T, et al. Does direct stenting with drug-eluting stents improve outcome? A meta-analysis of 10,900 patients. Catheter Cardiovasc Interv 2017;90:213-22.

37. Cook JR, Mhatre A, Wang FW, et al. Prolonged highpressure is required for optimal stent deployment as assessed by optical coherence tomography. Catheter Cardiovasc Interv 2014;83:521-7.

38. Saad M, Bavineni M, Uretsky BF, et al. Improved stent expansion with prolonged compared with short balloon inflation: A meta-analysis. Catheter Cardiovasc Interv 2018;92:873-80.

39. Waksman R, Kitabata H, Prati F, et al. Intravascular ultrasound versus optical coherence tomography guidance. J Am Coll Cardiol 2013;62:S32-40.
40. Bouma BE, Tearney GJ, Yabushita H, et al. Evaluation of intracoronary stenting by intravascular optical coherence tomography. Heart 2003;89:317-20.

41. Fitzgerald PJ, Oshima A, Hayase M, et al. Final results of the Can Routine Ultrasound Influence Stent Expansion (CRUISE) study. Circulation 2000;102:523-30.

42. Witzenbichler B, Maehara A, Weisz G, et al. Relationship between intravascular ultrasound guidance and clinical outcomes after drug-eluting stents: the assessment of dual antiplatelet therapy with drug-eluting stents (ADAPTDES) study. Circulation 2014;129:463-70.

43. Choi SY, Witzenbichler B, Maehara A, et al. Intravascular ultrasound findings of early stent thrombosis after primary percutaneous intervention in acute myocardial infarction: a Harmonizing Outcomes with Revascularization and Stents in Acute Myocardial Infarction (HORIZONS-AMI) substudy. Circ Cardiovasc Interv 2011;4:239-47.

44. Elgendy IY, Mahmoud A, Elgendy AY, et al. Outcomes With Intravascular Ultrasound-Guided Stent Implantation: A Meta-Analysis of Randomized Trials in the Era of DrugEluting Stents. Circ Cardiovasc Interv 2016;9:e003700.

45. Kim BK, Shin DH, Hong MK, et al. Clinical Impact of Intravascular Ultrasound-Guided Chronic Total Occlusion Intervention With Zotarolimus-Eluting Versus BiolimusEluting Stent Implantation: Randomized Study. Circ Cardiovasc Interv 2015;8:e02592.

46. Mariani J Jr, Guedes C, Soares P, et al. Intravascular ultrasound guidance to minimize the use of iodine contrast in percutaneous coronary intervention: the MOZART (Minimizing cOntrast utiliZation With IVUS Guidance in coRonary angioplas Ty) randomized controlled trial. JACC Cardiovasc Interv 2014;7:1287-93.

47. Ali ZA, Karimi Galougahi K, Nazif T, et al. Imaging- and physiology-guided percutaneous coronary intervention without contrast administration in advanced renal failure: a feasibility, safety, and outcome study. Eur Heart J 2016;37:3090-5.

48. Ali ZA, Maehara A, Généreux P, et al; ILUMIEN III: OPTIMIZE PCI Investigators. Optical coherence tomography compared with intravascular ultrasound and with angiography to guide coronary stent implantation (ILUMIEN III: OPTIMIZE PCI): a randomised controlled trial. Lancet 2016;388:2618-28.

49. Otake H, Kubo T, Takahashi H, et al. Optical Frequency Domain Imaging Versus Intravascular Ultrasound in Percutaneous Coronary Intervention (OPINION Trial): Results From the OPINION Imaging Study. JACC Cardiovasc Imaging 2018;11:111-23.

50. Jones DA, Rathod KS, Koganti S, et al. Angiography Alone 
Versus Angiography Plus Optical Coherence Tomography to Guide Percutaneous Coronary Intervention: Outcomes From the Pan-London PCI Cohort. JACC Cardiovasc Interv 2018;11:1313-21.

51. Wijns W, Shite J, Jones MR, et al. Optical coherence tomography imaging during percutaneous coronary intervention impacts physician decision-making: ILUMIEN I study. Eur Heart J 2015;36:3346-55.

52. Meneveau N, Souteyrand G, Motreff P, et al. Optical Coherence Tomography to Optimize Results of Percutaneous Coronary Intervention in Patients with Non-ST-Elevation Acute Coronary Syndrome: Results of the Multicenter, Randomized DOCTORS Study (Does Optical Coherence Tomography Optimize Results of Stenting). Circulation 2016;134:906-17.

53. Levine GN, Bates ER, Bittl JA, et al. 2016 ACC/ AHA Guideline Focused Update on Duration of Dual Antiplatelet Therapy in Patients With Coronary Artery Disease: A Report of the American College of Cardiology/ American Heart Association Task Force on Clinical Practice Guidelines: An Update of the 2011 ACCF/AHA/ SCAI Guideline for Percutaneous Coronary Intervention, 2011 ACCF/AHA Guideline for Coronary Artery Bypass Graft Surgery, 2012 ACC/AHA/ACP/AATS/PCNA/ SCAI/STS Guideline for the Diagnosis and Management of Patients With Stable Ischemic Heart Disease, 2013 ACCF/AHA Guideline for the Management of STElevation Myocardial Infarction, 2014 AHA/ACC Guideline for the Management of Patients With NonST-Elevation Acute Coronary Syndromes, and 2014 ACC/AHA Guideline on Perioperative Cardiovascular Evaluation and Management of Patients Undergoing Noncardiac Surgery. Circulation 2016;134:e123-55.

54. Kim BK, Hong MK, Shin DH, et al; RESET Investigators. A new strategy for discontinuation of dual antiplatelet therapy: the RESET Trial (REal Safety and Efficacy of 3-month dual antiplatelet Therapy following Endeavor zotarolimus-eluting stent implantation). J Am Coll Cardiol 2012;60:1340-8.

55. Gwon HC, Hahn JY, Park KW, et al. Six-month versus 12-month dual antiplatelet therapy after implantation of drug-eluting stents: the Efficacy of Xience/Promus Versus Cypher to Reduce Late Loss After Stenting (EXCELLENT) randomized, multicenter study. Circulation 2012;125:505-13.

56. Mauri L, Kereiakes DJ, Yeh RW, et al. Twelve or 30 months of dual antiplatelet therapy after drug-eluting stents. N Engl J Med 2014;371:2155-66.
57. Yeh RW, Secemsky EA, Kereiakes DJ, et al. Development and Validation of a Prediction Rule for Benefit and Harm of Dual Antiplatelet Therapy Beyond 1 Year After Percutaneous Coronary Intervention. JAMA. 2016;315:1735-49.

58. Dewilde WJ, Oirbans T, Verheugt FW, et al. Use of clopidogrel with or without aspirin in patients taking oral anticoagulant therapy and undergoing percutaneous coronary intervention: an open-label, randomised, controlled trial. Lancet 2013;381:1107-15.

59. Fiedler KA, Maeng M, Mehilli J, et al. Duration of Triple Therapy in Patients Requiring Oral Anticoagulation After Drug-Eluting Stent Implantation: The ISAR-TRIPLE Trial. J Am Coll Cardiol 2015;65:1619-29.

60. Morikawa S, Takabe W, Mataki C, et al. The effect of statins on mRNA levels of genes related to inflammation, coagulation, and vascular constriction in HUVEC. Human umbilical vein endothelial cells. J Atheroscler Thromb 2002;9:178-83.

61. LaRosa JC, Grundy SM, Waters DD, et al. Intensive lipid lowering with atorvastatin in patients with stable coronary disease. N Engl J Med 2005;352:1425-35.

62. Wang TJ, Yang YJ, Xu B, et al. Atorvastatin accelerates both neointimal coverage and re-endothelialization after sirolimus-eluting stent implantation in a porcine model: new findings from optical coherence tomography and pathology. Circ J 2012;76:2561-71.

63. Yamamoto H, Ikuta S, Kobuke K, et al. Difference in statin effects on neointimal coverage after implantation of drug-eluting stents. Coron Artery Dis 2014;25:290-5.

64. Im E, Cho YH, Suh Y, et al. High-intensity Statin Treatments in Clinically Stable Patients on Aspirin Monotherapy 12 Months After Drug-eluting Stent Implantation: A Randomized Study. Rev Esp Cardiol (Engl Ed) 2018;71:423-31.

65. Jeong HC, Ahn Y, Hong YJ, et al. Statin therapy to reduce stent thrombosis in acute myocardial infarction patients with elevated high-sensitivity C-reactive protein. Int J Cardiol 2013;167:1848-53.

66. Kamishirado H, Inoue T, Sakuma M, et al. Effects of statins on restenosis after coronary stent implantation. Angiology 2007;58:55-60.

Cite this article as: Patel DB, Shah R, Jovin IS. Improving outcomes of percutaneous coronary interventions in patients with stable ischemic heart disease. J Thorac Dis 2020;12(4):17401749. doi: $10.21037 /$ jtd.2019.11.17 